\title{
A Scattering Chamber for the Holifield Heavy Ion Research Facility
}

\author{
C. D. Goodman \\ J. E. Corum
}

\section{OAK RIDGE NATIONAL LABORATORY}




\section{DISCLAIMER}

This report was prepared as an account of work sponsored by an agency of the United States Government. Neither the United States Government nor any agency Thereof, nor any of their employees, makes any warranty, express or implied, or assumes any legal liability or responsibility for the accuracy, completeness, or usefulness of any information, apparatus, product, or process disclosed, or represents that its use would not infringe privately owned rights. Reference herein to any specific commercial product, process, or service by trade name, trademark, manufacturer, or otherwise does not necessarily constitute or imply its endorsement, recommendation, or favoring by the United States Government or any agency thereof. The views and opinions of authors expressed herein do not necessarily state or reflect those of the United States Government or any agency thereof. 


\section{DISCLAIMER}

Portions of this document may be illegible in electronic image products. Images are produced from the best available original document. 
Printed in the United States of America. Available from National Technical Information Service

U.S. Department of Commerce

5285 Port Royal Road, Springfield, Virginia 22161

Price: Printed Copy $\$ 3.50 ;$ Microfiche $\$ 3.00$ $4,4,00$

This report was prepared as an account of work sponsored by the United States Government. Neither the United States nor the Energy Research and Development Administration/United States Nuclear Regulatory Commission, nor any of their employees, nor any of their contractors, subcontractors, or their employees, makes any warranty, express or implied, or assumes any legal liability or responsibility for the accuracy, completeness or usefulness of any information, apparatus, product or process disclosed, or represents that its use would not infringe privately owned rights. 
Contract No. W-7405-eng-26

Physics Division

\section{A SCATTERING CHAMBER FOR THE HOLIFIELD}

HEAVY ION RESEARCH FACILITY

C. D. Goodman

J. E . Corum

Date Published - September 1977

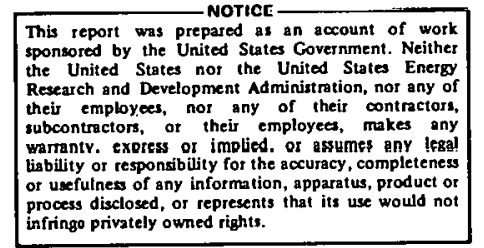

NOTICE This document contains information of a preliminary nature. It is subject to revision or correction and therefore does not represent a final report.

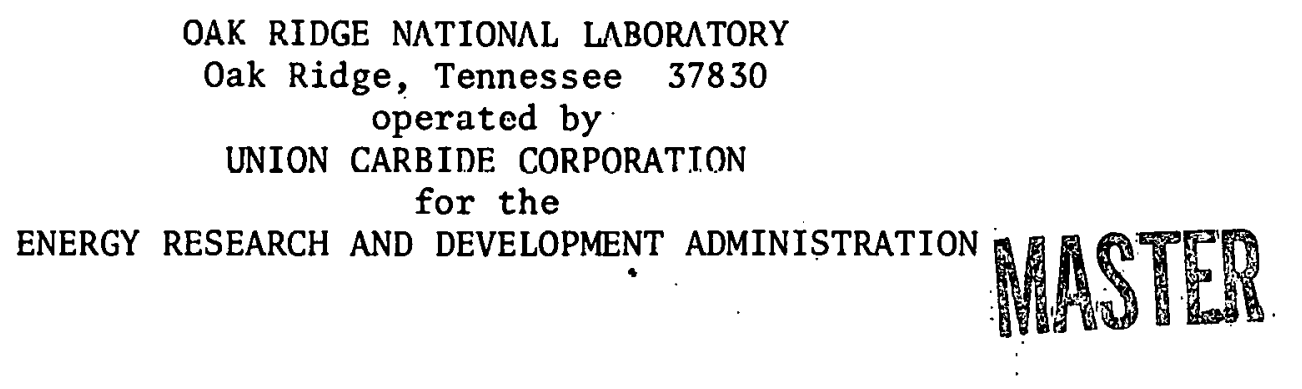


THIS PAGE

WAS INTENTIONALLY

LEFT BLANK 
CONTENTS

Page

ABSTRACT ........................ ].

I. INTRODUCTION: The Scattering Chamber's Relationship to

Other Tools. . . . . . . . . . . . . . . . . 1

II. GENERAL DESIGN PHILOSOPHY. . . . . . . . . . . . . 2

III. VACUUM VESSEL. . . . . . . . . . . . . . . . . 3

IV. VACUUM PUMPING . . . . . . . . . . . . . . . . . 3

V. DETECTOR MOTIONS ..................... . 4

VI. TARGET ladder. . . . . . . . . . . . . . . . . . 5

VII. FEED THROUGHS FOR SIGNAL, GAS LINE, AND COOLING. . . . . . . 6 VIII. FARADAY CUP, COLLIMATORS . . . . . . . . . . . . . 6 
THIS PAGE

WAS INTENTIONALLY

LEFT BLANK 


\section{ACKNOWLEDGEMENTS}

We thank John Eck, Edward Gross, Richard Stokes, and Victor Viola for preparing a report summarizing users' desires and providing a basis for scattering chamber specifications. We also thank Charles Foster for suggestions and discussions about the chamber design. We acknowledge perusal of the design drawings for the NASA-Lewis scattering chamber now at the Indiana University Cyclotron Facility and the drawings for the scattering chamber for GSI, Darmstadt. 
A SCATTERING CHAMBER FOR THE HOLIFIELD

HEAVY ION RESEARCH FACILITY

C. D. Goodman and J. E. Corum

\begin{abstract}
A conceptual design is presented for a 62-in.-diam. general purpose scattering chamber to be used for nuclear research with heavy ions. The detector rotation mechanism is based on large diameter (approx, 58 in.) peripherally driven rings. This leaves the central region open for detectors and other apparatus and permits the use of a perpendicular ring for rotating a detector out of the reaction plane. A precision target slide with provisions for removing the entire slide under vacuum is part of the design. Access and viewing ports on the dished top and in the reaction plane will be provided. Cryogenic pumping will be used to keep the vacuum free from hydrocarbon vapors, water vapor, and oxygen.
\end{abstract}

\title{
I. INTRODUCTION
}

The 25-MV tandem electrostatic accelerator and the cyclotron, separately and together, will provide a wide variety of heavy ions over a broad energy range. The research program will require the use of many different techni.ques for detection and identification of reaction products. We expect that various combinations of $\triangle E / E$, time-of-flight, and magnetic analysis will be employed in reaction studies, and to that end several different tools have been buill ur are planned for the various beam lines..

In the immediate future, experiments requiring magnetic analysis must use the Elbek spectrograph and a new beam line is planned to bring the direct tandem beam to it so that it can be used with either the cyclotron or the tandem. Future plans for a new magnetic spectrograph are discussed by Ford et al. 1 A facility expressly designed for time-of-flight work has already been installed adjacent to the Elbek spectrograph and, like the Elbek, will have access to beams from both accelerators.

A 30 -in. scattering chamber ${ }^{2}$ will continue to be used with the cyclotron beam. This chamber was designed for and is still used with $\Delta E / E$ solid-state counter telescopes. It also features a rigid sliding seal and extension tube that permits placing a detector $1 \mathrm{~m}$ from the target in the forward quadrant. 
The design of the proposed new chamber will emphasize features to accommodate experiment setups that cannot be used or can be used only with difficulty in the 30-in. chamber. Of course, we shall also make use of advances in technology and our experience since 1962. Some comparisons between the chambers will be made in the body of this report.

The purpose of this memorandum is twofold, first to inform the potential users of our plans, and second to solicit user comment on the design before the final engineering takes place.

\section{GENERAL DESIGN PHILOSOPHY}

The chamber is intended to provide apparatus for containing targets and detectors in a clean vacuum, for viewing the beam focus, for collecting the beam, and to provide precision motlons for rolating deteitors around the target. Figures 1 and 2 show elevation and plan views of the proposed design.

We plan to provide all the hardware necessary to perform certain welldefined experiments in which solid-state detectors are rotated about solidfilm targets and beam collection is done in a standard faraday cup with a current integrator.

We recognize that experimenters will from time to time use unisual detector arrangements, gas targets, and other devices which may be novel and complex. We cannot presume to anticipate the designs of novel apparatus. Rather, we shall try to design the chamber so that it can be stripped down to its bare essentials and then equipped with special accessories. We hope that the design will insure that the experimenter is not encumbered by special features that may be desirable for other experiments but irrelevant to his experiment.

We shall, however, consider the standard rotation mechanism as part of the bare essentials not to be stripped, because we feel that the experimenter should not have to align detector mounts, target holders, and faraday cup for standard experiments. On the other hand, out-of-plane detectors, gas targets, and motor-driven radial motion devices, for example, shall be considered as accessories that are completely removabile.

While we can tolerate an experimenter's deteriorating the vacuum during his uwn run, we will insist that plastic parts, leaky gas countcrs, or any parts that adversely affect the vacuum be removed after the experimenter's run. We shall design the basic parts to maintain a clean vacuum. 
III. VACUUM VESSEL

The vacuum vessel shall consist of a 62 -in. diam. ring, flat bottom, and a dished top. The cyclindrical ring shall contain twelve 6 -in. ports at beam height. One of these ports will be used for the beam entrance, and the opposite port shall be used for attaching an exit tube with faraday cup. Six 2-in. ports will be provided below the beam plane for feed throughs. The dish top will contain six 6-in. ports.

We intend to minimize but not entirely eliminate the use of 0-rings made from organic materials. At very least we require $0-r i n g s$ for the top seal and for the rotating seal around the target tube. We will evaluate each seal individually to decide where metal gaskets should be used and where the advantages of 0-rings outweigh the disadvantage of slight outgassing. We believe that a small number of viton 0-rings is tolerable.

All ports will be machined to accommodate conflat flanges with copper gaskets. At the experimenter's choice, flanges may be equipped with safety glass covers for viewing; metal blank-off covers; gas, cooling, or electrical feed throughs; or special apparatus built by the experimenter.

A final decision. on material for the vacuum vessel has not been made. The cost for labor and materials is substantially less for aluminum than for stainless steel. The question yet to be answered is whether we would expect vacuum problems with an aluminum system.

An electric lifting mechanism will be provided for lifting the top and swinging it to one side for access to the inside of the chamber. As is the case with the existing 30-in. chamber, bolting of the top is not required and locating pins will be used to provide a unique and reproducible orientation.

\section{VACUUM PUMPING}

We feel that the most important function of the vacuum system is to keep the chamber free from gases and vapors that might react with active targets or condense on cold detectors. We also want to avoid pump oil and hydrocarbon vapors to minimize the carbon buildup on targets. We therefore plan to use cryogenic pumping.

A discussion of vacuum pumping is given, along with a graph of pressure vs time for various pump systems, in a recent Holifield HeavyIon Research Facility Newsletter. ${ }^{3}$ We plan to use a pumping system similar to that used for the beam lines and aim at achieving an operating pressure of less than $10^{-7}$ torr in the chamber. 


\section{DETECTOR MOTIONS}

The basic turntable mechanism in this chamber consists of large diameter rings (approximately 58 in.) on large diameter bearings. This rotating structure is supported from a rigid frame outside the vacuum, and flexible bellows seals are used where the supports go through the bottom of the vacuum vessel. Two rotating rings are driven by small motors ${ }^{4}$ inside the vacuum through peripheral pinion gears. The first and third rings (counting from the bottom) are fixed and the second and fourth rotate.

A hollow center column is also supported from the same external frame, and it also is decoupled mechanically from the bottom plate of the vacuum vessel so that the relative centering and alignment of the rotating rings and the center column will not be changed by flexing of the bottom plate under vacuum loading.

A single permanent spoke will be provided from each rotating ring to the center column to use as a detector mount. These spokes will have radial scales in centimeters measured from the center of rotation and an array of tapped mounting holes and precision drilled locating pin holes.

One advantage of this design is that the region inside the rings is open, making space available for large detectors. Also, signal cables and gas lines from the detectors can be strapped to the spokes and run toward the center and then brought out through nonrotating feed throughs with minimal flexing of the cables and very little chance of getting caught on other rotating mechanisms.

The open center region also permits using a full ring for rotating an out-of-plane detector mount. A 22-in. diam. rotating ring in a vertical plane can be attached to the side of one of the permanent spokes to provide azimuthal and polar rotations of a detector.

Provisions will be made for mounting additional, removable spokes for multiple detectors or auxiliary equipment. In addition, provision will be made to mount removable spokes on the fixed rings. These might be used, for example, to mount nonrotating monitor detectors.

With no detectors installed, each ring can rotate continuously in either direction. The permanent spokes, however, will be equipped with microswitches that can sense tabs placed on other moving or fixed spokes to limit the range of rotation.

Engraved angle scales on the outer rims of the rotating rings will provide the primary angle readings. Since the vernier does not move, a single, fixed TV camera can read the angles of both horizontal rings. A special viewing port will be provided for such a camera. An angle encoder will be driven by the peripheral gear on each ring. This will provide 
the potential for computer readout and control, but a computer interface is not included in the present scope of the design project.

Because of the large diameter of the angle scales, it should be easy to read to $0.01^{\circ}$. However, such accuracy is not usually meaningful because of uncertainties in the beam spot position and other alignment uncertainties.

\section{TARGET LADDER}

We propose to use a target ladder rather than a target wheel in this chamber, since the ladder provides less interference with rotating detectors than a wheel and seems more adaptable to vacuum transfer systems for chemically active targets.

We plan to achieve the positioning precision and selection simplicity of the Geneva wheel of the 30-in. chamber by using a linear Geneva cam to move the target ladder incrementally in 1.5-in. units. This dimension is chosen to accommodate existing ORIC target frames.

In addition, we will provide a manually operated fine control that will raise or lower the entire target holder $1 / 4$ in. from the central position. This manual adjustment will be lockable in the central position. When it is unlocked, a warning light will appear on the control panel. Thus, in normal locked operation, targets will be selected by number and always centered. If an experimenter burns a hole in the center of his target and wants to displace it to strike an unburnt section, he can do so at his own peril with the manual control. If he relocks the manual control, he is back to the center of all targets.

The entire target slide can be retracted into a vacuum lock. This would normally be done when the chamber is being roughed down or let up to air. The vacuum lock can also be detached and carried to a target preparation laboratory, providing target transfer in vacuum.

The target rotation mechanism is motor driven and located below the chamber. Its angle scale is far from the detector angle scales, and we will either provide a separate TV camera for it or an optical system to make it visible to the other TV camera.

The target rotation mechanism contains the only moving vacuum seal on this chamber. 


\section{VII . FEED THROUGHS FOR SIGNALS, GAS LINES, AND COOLING}

We would like to avoid having any large number of exposed cables or plastic tubes inside the vacuum.

As we pointed out above, it is possible to strap cables to the detector carrying spokes. We will provide a few $50 \Omega$ cables encased in metal bellows that can be attached to the detector arms. We will also provide metal bellows gas lines. In addition, we will provide feed through arrays with BNC and SHV connectors on plates that fit the chamber ports. We will also provide feed throughs with reentrant, thin-wall stainless lead-ins for thermal isolation of cooling lines. These will be fitted with flexible bellows hose.

Special feed through requirements can easily be accommodated, and we shall not try to anticipate all needs before using the chamber.

\section{FARADAY CUP AND COLLIMATORS}

A faraday cup with magnetic electron suppressiun will be provided that can attach to one of the 6 -in. ports on the chamber.

Four jaw collimator slits will be placed in the beam lines at the locations of beam waists as calculated for the ion optics of the beam line.

A retractable, four-jaw cleanup slit will be provided that an experimenter may use, if he wishes, on the entrance port of the chambcr.

One of the positions on the target slide will be used for a phosphor, and a dedicated TV camera (in addition to the one used for reading angle scales) will be used to view the target spot.

Annther target position will be equipped with a four-quadrant current readout to verify the centering of the beam. 


\section{RËFERENCES}

1. J. L. C. Ford, Jr ;, H. A. Ennge; J. R. Erskine; D. L. Hendrie; and M. J. LeVine; (ORNL/TM-5687):

2. Designed in 19.62 by C. D. Goodman and R. M. Beckers.

3. HHIRF Newsletter No: $8, \mathrm{p}: 6$ (1977).

4: We have successfully used silo-syn SS50V motors in vacuum and wili choose the same or similar motors for this appilication. 


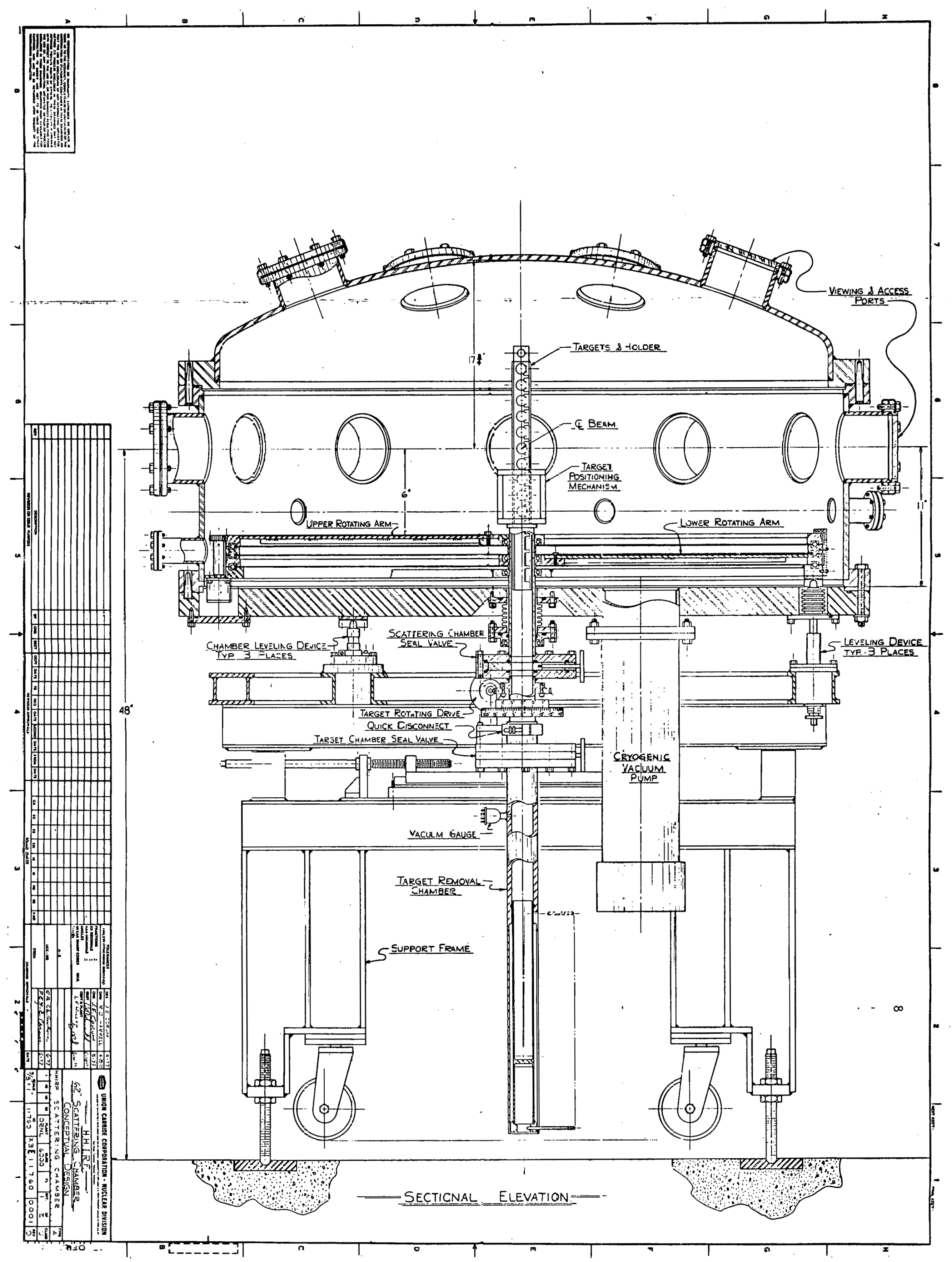

FIG. 1. Elesation view of the proposed scatterirg chamber design. 
ORNL/TM-6028

\section{INTERNAL DISTRIBUTION}

$\begin{aligned} \text { 1. } & \text { J. B. Ball } \\ 2 . & \text { F. E. Bertrand } \\ 3 . & \text { C. R. Bingham } \\ 4 . & \text { T. P. Cleary } \\ 5-14 . & \text { J. E. Corum } \\ 15 . & \text { R. L. Ferguson } \\ 16 . & \text { J. L. C. Ford } \\ 17 . & \text { C. B. Fulmer } \\ 18-27 . & \text { C. D. Goodman } \\ 28 . & \text { E. E. Gross } \\ 29 . & \text { R. L. Hahn } \\ 30 . & \text { M. L. Halbert } \\ 31 . & \text { J. W. Johnson } \\ 32 . & \text { H. J. Kim } \\ 33 . & \text { J. A. Martin }\end{aligned}$

\author{
34. P. D. Miller \\ 35. F. E. Obenshain \\ 36. R. Piercey \\ 37. F. Plasil \\ 38-47. R. L. Robinson \\ 48. D. Shapira \\ 49. C. B. Smith \\ 50. P. H. Stelson \\ 51. R. G. Stokstad \\ 52. L. V. Wilson \\ 53. A. Zucker \\ 54-55. Central Research Library \\ 56-57. Laboratory Records \\ 58. Laboratory Records, ORNL-RC \\ 59. ORNL Patent Office \\ 60. Document Reference Section
}

\section{EXTERNAL DISTRIBUTION'}

61. M. Blann, University of Rochester, Department of Chemistry, Rochester, NY 14627

62. D. A. Bromley, Yale University, Department of Physics, New Haven, CT 06520

63. W. L. Brown, Bell Laboratories, 600 Mountain Avenue, Murray Hill, NJ 07974

64. J. C. Corne11, CSIR National Accelerator Project, Box 320, Stellenbosch 7600 , South Africa

65. J. G. Cramer, University of Washington, Nuclear Physics Laboratory, Seattle, WA 98195

66. John Eck, Kansas State University, Physics Division, Manhattan, KS 66502

67. H. Enge, Massachusetts Institute of Technology, Department of Physics, Building 46, Cambridge, MA 02139

68. C. C. Foster, University of Indiana, Physics Department, Bloomington, IN 47401

69. H. A. Grunder, Lawrence Berkeley Laboratory, Berkeley, CA 94702

70. J. H. Hamilton, Vanderbilt University, Department of Physics and Astronomy, Nashville, TN 37235

71. n, Hillis, Niels Bohr Institute, Riso, DK 4000, Roskilde, Denmark

72. J. R. Huizenga, University of Rochester, Nuclear Structure Research Laboratory, Rochester, NY 14627

73. E. V. Hungerford, University of Houston, Department of Physics, Houston, TX 77004

74. J. Natowitz, Texas A \& M University, Cyclotron, College Station, TX 77843 
EXTERNAL DISTRIBUTION (continued)

75. N. R. Roberson, Duke University, Physics Department, Durham, NC 27706

76. R. H. Stokes, Los Alamos Scientific Laboratory, Los Alamos, NM 87545

77. C. A. Tobias, University of California, Donner Laboratory, Berkeley, CA 94720

78. J. P. Unik, Argonne National Laboratory, Building 200, Argonne, IL 60439

79. V. Viola, University of Maryland, Department of Chemistry, College Park, MD 20742

80. H. Wegner, Brookhaven National Laboratory, Department of Physics; Upton, NY 1197.3

81. M. Zisman, Lawrence Berkeley Laboratory, Berkeley, CA 94720

82. Research and Technicall Support Division, ERDA-ORO

83-109. Technical Information Center, P.0. Box 62, Oak Ridge, TN 37830 